\title{
PV systems linked to the grid: Parameter identification with a heuristic procedure
}

\author{
L. Fialho $^{\mathrm{a}, \mathrm{b}}$, R. Melício ${ }^{\mathrm{a}, \mathrm{b}, *}$, V.M.F. Mendes ${ }^{\mathrm{b}, \mathrm{c}}$, A. Estanqueiro $^{\mathrm{d}}$, M. Collares-Pereira $^{\mathrm{b}}$ \\ a IDMEC/LAETA, Instituto Superior Técnico, Universidade de Lisboa, Lisbon, Portugal \\ ${ }^{\mathrm{b}}$ Department of Physics, Universidade de Évora, Largo dos Colegiais 2, 7004-516 Évora, Portugal \\ ' Department of Electrical Engineering and Automation, Instituto Superior de Engenharia de Lisboa, R. Conselheiro Emídio Navarro, 1950-062 Lisbon, Portugal \\ ${ }^{\mathrm{d}}$ National Laboratory of Energy and Geology, Estrada do Paço do Lumiar, 1649-038 Lisbon, Portugal
}

\section{A R T I C L E I N F O}

Article history:

Received 13 August 2014

Revised 26 January 2015

Accepted 29 January 2015

\section{Keywords:}

PV system

Power electronics

Parameter identification

Shading effect

Modeling

Simulation and experimental results

\begin{abstract}
A B S T R A C T
This paper focuses on a PV system linked to the electric grid by power electronic converters, identification of the five parameters modeling for photovoltaic systems and the assessment of the shading effect. Normally, the technical information for photovoltaic panels is too restricted to identify the five parameters. An undemanding heuristic method is used to find the five parameters for photovoltaic systems, requiring only the open circuit, maximum power, and short circuit data. The $I-V$ and the $P-V$ curves for a monocrystalline, polycrystalline and amorphous photovoltaic systems are computed from the parameters identification and validated by comparison with experimental ones. Also, the $I-V$ and the $P-V$ curves under the effect of partial shading are obtained from those parameters. The modeling for the converters emulates the association of a DC-DC boost with a two-level power inverter in order to follow the performance of a testing commercial inverter employed on an experimental system.
\end{abstract}

(c) 2015 Elsevier Ltd. All rights reserved.

\section{Introduction}

The demand for sources of sustainable energy, the shortage of fossil fuels and the need for carbon footprint reduction have resulted in a global awareness of the importance of alternative energy sources and efficiency in the use of energy [1]. Renewable energy sources are likely to have a significant role in the world energy supply in the upcoming future. Among the renewable energy sources, solar energy has ubiquity and abundance [2,3]. Hence, if technology find is way through the development of cheaper converts of solar into electric energy and with better efficiency, solar energy will eventually be the most important source of sustainable energy for power supply, delivering energy in the neighborhood of where it is needed [4,5].

Apart from the solar thermal exploitation, the spreading of PV systems is being encouraged by delivering energy in the neighborhood of where it is needed tariffs and by the price drop in crystalline cells [6]. At present, significant photovoltaic (PV) deployment has occurred, particularly in Germany, Spain and Japan [7]. PV energy has exceptional conditions in Portugal to be

\footnotetext{
* Corresponding author at: IDMEC/LAETA, Instituto Superior Técnico, Universidade de Lisboa, Lisbon, Portugal. Tel.: +351 266745 372; fax: +351 266745394

E-mail addresses: ruimelicio@gmail.com (R. Melício), vfmendes@deea.isel.pt (V.M.F. Mendes).
}

exploited, because this European country has significant levels of solar radiation to go into exploitation. Sunshine hours in the mainland of Portugal vary between 1800 and $3100 \mathrm{~h}$ per year [8]. Hence, the country has a huge potential for solar energy exploitation, the biggest PV system is in Moura, with an installed capacity of $46 \mathrm{MWp}$.

A PV system directly converts solar energy into direct electric current energy. Solar cells are made of several types of semiconductors using different manufacturing processes [9]. The energy converted by a solar cell depends on the substrate properties, on the temperature of the junction and on the incoming solar radiation [10], known as irradiation. The solar radiation is composed of photons with different levels of energy. But not all photons are useful in order to originate the photo current, the remainder energy passes by or is adsorbed as thermal agitation, contributing to the definition of the temperature on the solar cell [11].

A PV array may be either a panel or a set of panels connected to form large PV systems with or without tracking systems. But, even with tracking systems a correct consideration of the space for the operational neighborhood have to be assessed to avoid mutual shading.

Power-electronic converters are usually used to process the direct electric current coming from PV system, for instance, are used as inverters to deliver an alternate current and may be used to: regulate the voltage and current at the load, control the power 